\section{Acknowledgments}

The authors thank Catherine Murray (The Rockefeller University) for editing the manuscript. This work was supported by grants from the Gates Foundation through the Grand Challenges in Global Health initiative (to all authors) and funded in part by the Greenberg Medical Research Institute, the Ellison Medical Foundation, the Starr Foundation, the Ronald A. Shellow Memorial Fund, the Richard Salomon Family Foundation (to C.M. Rice), and the NIH through the NIH Roadmap for Medical Research, grant 1 R01 DK085713-01 (to C.M. Rice and A. Ploss). C.M. Rice is an Ellison Medical Foundation Senior Scholar in Global Infectious Diseases.

Address correspondence to: Alexander Ploss or Charles M. Rice, Center for the Study of Hepatitis C, The Rockefeller University, 1230 York Avenue, Box 64, New York, NY 10065. Phone: 212.327.7066; Fax: 212.327.7048; E-mail: aploss@rockefeller.edu (A. Ploss). Phone: 212.327.7046; Fax: 212.327.7048; E-mail: ricec@rockefeller.edu (C.M. Rice).

1. Alter MJ. Epidemiology and prevention of hepatitis B. Semin Liver Dis. 2003;23(1):39-46.

2. Shepard CW, Finelli L, Alter MJ. Global epidemiology of hepatitis C virus infection. Lancet Infect Dis. 2005;5(9):558-567.

3. Ploss A, et al. Persistent hepatitis $C$ virus infection in microscale primary human hepatocyte cultures. Proc Natl Acad Sci U S A. In press.

4. Mercer DF, et al. Hepatitis C virus replication in mice with chimeric human livers. Nat Med. 2001;7(8):927-933.

5. Meuleman P, et al. Morphological and biochemical characterization of a human liver in a UPA-SCID mouse chimera. Hepatology. 2005;41(4):847-856.

6. Kaul A, Woerz I, Meuleman P, Leroux-Roels G, Bartenschlager R. Cell culture adaptation of hepatitis $\mathrm{C}$ virus and in vivo viability of an adapted variant. J Virol. 2007;81(23):13168-13179.

7. Meuleman P, Leroux-Roels G. The human liveruPA-SCID mouse: a model for the evaluation of antiviral compounds against $\mathrm{HBV}$ and HCV. Antiviral Res. 2008;80(3):231-238.

8. Brezillon NM, et al. Rescue of fertility in homozygous mice for the urokinase plasminogen activator transgene by the transplantation of mouse hepatocytes. Cell Transplant. 2008;17(7):803-812.

9. Heckel JL, Sandgren EP, Degen JL, Palmiter RD, Brinster RL. Neonatal bleeding in transgenic mice expressing urokinase-type plasminogen activator. Cell. 1990;62(3):447-456.

10. Suemizu H, et al. Establishment of a humanized model of liver using NOD/Shi-scid IL2Rgnull mice. Biochem Biophys Res Commun. 2008;377(1):248-252.

11. Song $X$, et al. A mouse model of inducible liver injury caused by tet-on regulated urokinase for studies of hepatocyte transplantation. Am J Pathol. 2009;175(5):1975-1983.

12. Weglarz TC, Degen JL, Sandgren EP. Hepatocyte transplantation into diseased mouse liver. Kinetics of parenchymal repopulation and identification of the proliferative capacity of tetraploid and octaploid hepatocytes. Am J Pathol. 2000;157(6):1963-1974

13. Azuma H, et al. Robust expansion of human hepatocytes in Fah-/-/Rag2-/-/Il2rg-/- mice. Nat Biotechnol. 2007;25(8):903-910.

14. Bissig KD, Le TT, Woods NB, Verma IM. Repopulation of adult and neonatal mice with human hepatocytes: a chimeric animal model. Proc Natl Acad Sci U S A. 2007;104(51):20507-20511.

15. Grompe $M$, et al. Pharmacological correction of neonatal lethal hepatic dysfunction in a murine model of hereditary tyrosinaemia type I. Nat Genet. 1995;10(4):453-460.
16. Bissig K-D, et al. Human liver chimeric mice provide a model for hepatitis $\mathrm{B}$ and $\mathrm{C}$ virus infection and treatment. J Clin Invest. 2010;120(3):924-930.

17. Dandri $M$, et al. Repopulation of mouse liver with human hepatocytes and in vivo infection with hepatitis B virus. Hepatology. 2001;33(4):981-988.

18. Liang $\mathrm{Y}$, et al. Visualizing hepatitis $\mathrm{C}$ virus infections in human liver by two-photon microscopy. Gastroenterology. 2009;137(4):1448-1458.

19. Frevert U, Usynin I, Baer K, Klotz C. Plasmodium sporozoite passage across the sinusoidal cell layer. Subcell Biochem. 2008;47:182-197.

20. VanBuskirk KM, et al. Preerythrocytic, liveattenuated Plasmodium falciparum vaccine candidates by design. Proc Natl Acad Sci U S A. 2009;106(31):13004-13009.

21. Morosan S, et al. Liver-stage development of Plasmodium falciparum, in a humanized mouse model. J Infect Dis. 2006;193(7):996-1004.

22. Legrand $N$, et al. Humanized mice for modeling human infectious disease: challenges, progress, and outlook. Cell Host Microbe. 2009;6(1):5-9.

23. Shultz LD, Ishikawa F, Greiner DL. Humanized mice in translational biomedical research. Nat Rev Immunol. 2007;7(2):118-130.

24. Sullivan GJ, et al. Generation of functional human hepatic endoderm from human induced pluripotent stem cells. Hepatology. 2010;51(1):329-335.

25. Si-Tayeb K, et al. Highly efficient generation of human hepatocyte-like cells from induced pluripotent stem cells. Hepatology. 2010;51(1):297-305.

26. Snykers S, De Kock J, Rogiers V, Vanhaecke T. In vitro differentiation of embryonic and adult stem cells into hepatocytes: state of the art. Stem Cells. 2009;27(3):577-605.

27. Kneteman NM, Mercer DF. Mice with chimeric livers: who says supermodels have to be tall? Hepatology. 2005;41(4):703-706.

28. Adams DH, Eksteen B. Aberrant homing of mucosal $\mathrm{T}$ cells and extra-intestinal manifestations of inflammatory bowel disease. Nat Rev Immunol. 2006;6(3):244-251.

29. Ploss A, Rice CM. Towards a small animal model for hepatitis C. EMBO Rep. 2009;10(11):1220-1227.

\title{
Bidirectional homing of Tregs between the skin and lymph nodes
}

\author{
Hironori Matsushima and Akira Takashima
}

Department of Medical Microbiology and Immunology, University of Toledo College of Medicine, Ohio.

\begin{abstract}
Although several homing receptors are known to be differentially expressed by Tregs in lymphoid tissues compared with those found in peripheral tissues, it remains unclear whether these cells traffic between the two locations. In this issue of the JCI, Tomura et al. report steadystate Treg migration from the skin to draining LNs in mice. Furthermore, they report that not only does skin inflammation exacerbate LN-directed Treg homing, it also triggers reverse circulation of Tregs from LNs to skin, whereby these cells contribute to regulation of the immune response. These results now form a new framework for our understanding of Treg homing.
\end{abstract}

Conflict of interest: The authors have declared that no conflict of interest exists.

Citation for this article: J Clin Invest. 2010; 120(3):653-656. doi:10.1172/JCI42280.
Memory T cells are disseminated to lymphoid and nonlymphoid tissues throughout the body, and their migration to respective tissues is tightly regulated by adhesion mol- ecules and chemokine receptors (Table 1). For example, memory $\mathrm{T}$ cells that infiltrate the skin express a unique adhesion molecule, known as cutaneous lymphocyte-associated antigen (CLA), which is produced from P-selectin glycoprotein ligand-1 through posttranscriptional carbohydrate modification by fucosyltransferase VII. Skin-homing memory T cells also express specific chemokine receptors: CCR4, CCR6, and CCR10. In contrast, memory $T$ cells that preferentially circulate through lymphoid tissues express CD62 ligand (CD62L; also known as L-selectin) and CCR7 (1). 


\section{Table 1}

Differential expression of homing receptors by skin-homing versus LN-homing memory T cells

$\begin{array}{lcc}\text { Target tissue } & \text { Homing receptor } & \text { Corresponding ligand(s) } \\ \text { Skin } & \text { CLA } & \text { E-selectin } \\ \text { Skin } & \text { CCR4 } & \text { CCL17, CCL22 } \\ \text { Skin } & \text { CCR6 } & \text { CCL20 } \\ \text { Skin } & \text { CCR10 } & \text { CCL27, CCL28 } \\ \text { LN } & \text { CD62L } & \text { PNAd } \\ \text { LN } & \text { CCR7 } & \text { CCL19, CCL21 }\end{array}$

PNAd, peripheral lymph node addressin.

\section{Skin-resident Treg populations}

The entire skin surface of an adult human is populated with approximately $2 \times 10^{10}$ $\mathrm{T}$ cells, a majority of which express CLA, CCR4, and CCR6. Since approximately $10^{10} \mathrm{~T}$ cells circulate in peripheral blood, it has been estimated that normal skin contains twice as many $\mathrm{T}$ cells as are present in the blood circulation (2). Importantly, significant fractions $(5 \%-20 \%)$ of those human skin-resident $\mathrm{T}$ cells appear to represent Tregs based on the phenotype of $\mathrm{CD} 4^{+} \mathrm{CD} 25^{\text {hi }} \mathrm{CD} 69^{\text {lo }}$ and the expression of Foxp3, a master transcriptional regulator of Treg development and function $(2,3)$. Conversely, large fractions of blood-circulating human Tregs express CLA (80\%) and CCR6 (73\%) (4). Thus, the skin, an outermost organ constantly exposed to external insults, appears to serve as a major site for the immunosuppressive action of Tregs. In fact, Foxp3-deficient scurfy mice develop autoimmune inflammatory lesions primarily in the skin and lung (5).

Analogous to homing mechanisms for memory T cells, adhesion molecules and chemokine receptors regulate tissue-specific trafficking of Tregs as well. A majority of Tregs found in secondary lymphoid tissues express CD62L and CCR7. In adoptive transfer experiments, Tregs isolated from CD62L-deficient mice were far less efficient than WT Tregs in their homing to peripheral LNs and spleen as well as in suppressing the onset of acute graftversus-host disease (6). Likewise, adoptively transferred $C C R 7^{-1-}$ Tregs failed to achieve LN-directed homing and, thus, to suppress antigen-specific proliferation of $\mathrm{CD}^{+}$naive $\mathrm{T}$ cells $(7,8)$. Similar observations have been made in NOD type 1 diabetes and cardiac allograft models $(9,10)$. Because CD62L $L^{-/-}$Tregs and CCR7 $7^{-/-}$Tregs are both comparable to their WT counterparts with respect to their in vitro suppressive potentials, these observations imply that CD62L/CCR7-dependent homing of Tregs to secondary lymphoid tive function.

A distinct Treg population expressing CD103 (also known as integrin $\left.\alpha_{E}\right)$ has been recently identified. These CD $103^{+}$Tregs are characterized by elevated expression of conventional memory $\mathrm{T}$ cell markers (e.g., CD44, CD54, CD29, and CD69) and selective migratory responses to inflammatory chemokines (11). Importantly, CD103 is expressed by skin-resident Tregs (which account for greater than $20 \%$ of $\mathrm{CD}^{+}$ $\mathrm{T}$ cells in normal mouse skin), and its functional contribution has been demonstrated in antibody-blocking and CD103-/Treg-transfer experiments $(12,13)$. Upon intradermal OVA injection, adoptively transferred, OVA-reactive CD103-CD62 $\mathrm{L}^{+}$ Tregs acquired the expression of CD103, CCR4, and CLA, while losing CCR7 expression (12). Moreover, CCR4 $4^{-/}$Tregs and $C L A^{-/-}$Tregs both exhibited impaired skin homing, signifying the equally important roles of this chemokine receptissues is required for their in vivo protec- tor and adhesion molecule $(12,14)$. The skin inflammation observed in the scurfy mouse is preventable by the transfer of WT Tregs, but not $C L A^{-/-}$Tregs (15). Homing of Tregs to Leishmania major-infected skin lesions requires not only CCR4, but also CCR5 (16). Thus, Tregs expressing selected homing receptors preferentially migrate to the skin, where they presumably suppress the activation of effector $\mathrm{T}$ cells recognizing autoantigens or innocuous environmental antigens.

\section{Direct tracking of Treg migration from the skin to draining LNs}

As described above, Tregs employ distinct homing receptors for their preferential migration to lymphoid versus nonlymphoid epithelial tissues. A key question is whether Tregs are capable of trafficking between the two locations. In their current study in this issue of the JCI, Tomura et al. attempt to address this question by selectively "tagging" the skin-resident Tregs with the Kaede protein (17). Kaede (Acer palmatum, Japanese maple) decorates the autumn scenery by rapidly changing leaf color (Figure 1). The leaf is green during the summer because of the presence of chlorophyll, which also masks other pigments such as carotenoids. In the fall, the leaf turns bright red because of proteasedependent degradation of chlorophyll and de novo synthesis of anthocyanins. Kaede protein, named after the Japanese maple because of the parallel color change, is one of the recently developed photoconvertible fluorescent proteins that change their emission spectra in response to light exposure. Cloned from a stony coral, Trachyphyllia geoffroyi, Kaede undergoes
A

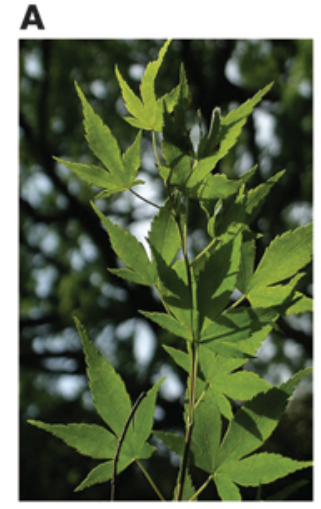

B

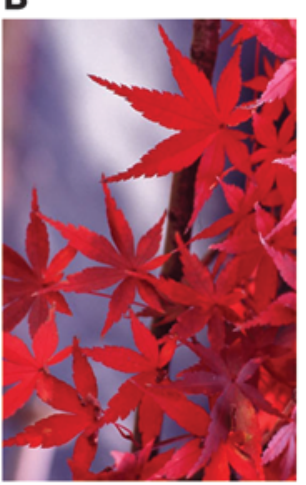

C

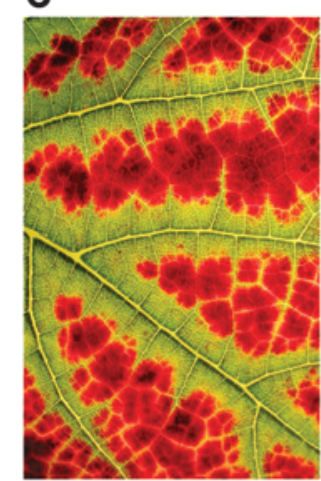

Figure 1

The Kaede (Japanese maple) leaf changes color seasonally. (A) During summer, the leaf is green due to the presence of chlorophyll. (B and $\mathbf{C}$ ) In the fall, protease-dependent degradation of chlorophyll and de novo synthesis of anthocyanins turn the leaf red. 


\section{A Steady-state skin}

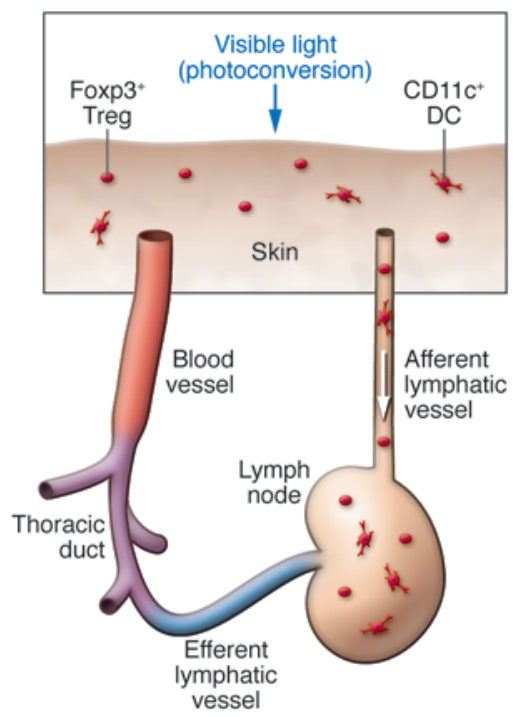

B DNFB-induced allergic contact dermatitis

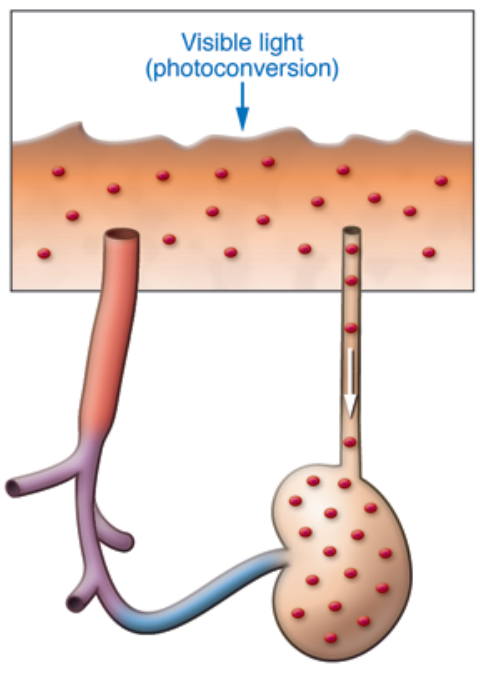

C DNFB-induced allergic contact dermatitis

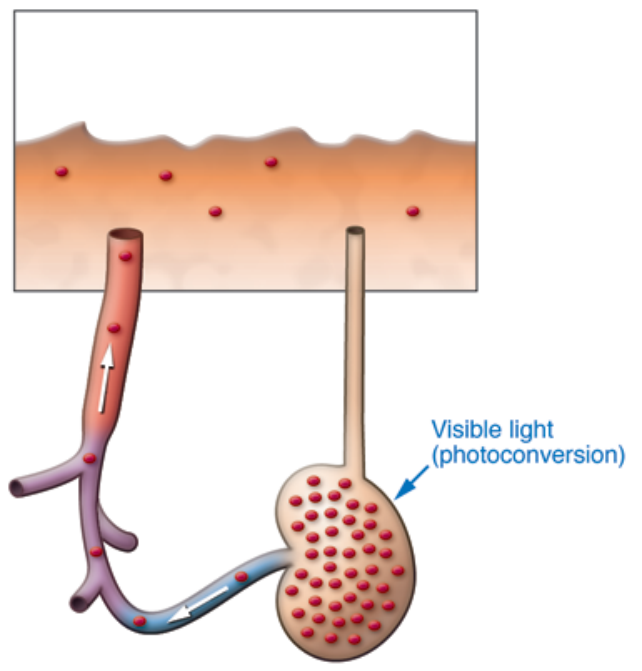

Figure 2

Treg trafficking between the skin and draining LNs. In their study in this issue of the $\mathrm{JCl}$, Tomura et al. used mice expressing the photoconvertible Kaede protein to directly track Treg migration between the skin and LNs in the steady state (A) and during DNFB-induced allergic contact dermatitis (B and C) (17). (A) Upon photoconversion from green to red of skin-resident cells, Kaede-red CD4+Foxp3 ${ }^{+}$Tregs and Kaede-red CD11 $\mathrm{C}^{+}$DCs became detectable in draining LNs, representing steady-state homing of Tregs and DCs from the skin to LNs. They presumably migrate through afferent lymphatic vessels. (B) DNFB-induced allergic contact dermatitis lesions contained increased numbers of Foxp3+ Tregs. An even more striking increase was observed in the numbers of Kaede-red Foxp3+ Tregs in the draining LNs, demonstrating accelerated Treg homing from inflamed skin. (C) Upon photoconversion of LN-resident cells, Kaede-red Foxp3+ Tregs became detectable in the DNFB-induced allergic contact dermatitis lesions. They presumably achieve this reverse migration by moving through efferent LVs, the thoracic duct, and blood vessels.

a green-to-red conversion within a few minutes after exposure to ultraviolet or violet light (18). Kaede protein contains an internal tripeptide, His ${ }^{62}-\mathrm{Tyr}^{63}-\mathrm{Gly}^{64}$, serving as a green-emitting chromophore like other GFP species, but undergoes unusual photocleavage at His ${ }^{62}$, thereby creating a new red-emitting chromophore (19). In Kaede-Tg mice, all the cell types constitutively exhibit Kaede-green fluorescence signals. Upon skin exposure to violet light, however, only those cells in the exposed skin begin to emit Kaede-red fluorescence signals.

Tomura et al. report that 24 hours after exposure of the abdominal skin of Kaede-Tg mice to violet light, small numbers of Kaede-red cells became detectable in the draining axillary LNs, but not in nondraining cervical or popliteal LNs (17). This cell population was composed of roughly equal numbers of $\mathrm{CD}^{+} \mathrm{T}$ cells and CD $11 c^{+}$DCs. Importantly, a significant fraction (approximately 20\%) of Kaedered $\mathrm{CD} 4^{+} \mathrm{T}$ cells expressed Foxp3, demonstrating steady-state trafficking of Tregs from the skin to draining LNs (Figure 2A) (17). To study skin-directed Treg hom- ing further, the authors intercrossed the Kaede-Tg mice with Foxp3 reporter mice and then induced allergic contact dermatitis by sensitization with 2,4-dinitro1-fluorobenzene (DNFB) on the dorsal skin, followed by DNFB challenge on the abdominal skin. The resulting inflammatory skin lesions were found to contain roughly 5-fold more Foxp $3^{+}$Tregs compared with control skin sites challenged with vehicle alone. An even more striking ( 20-fold) increase was observed in the numbers of Kaede-red Foxp $3^{+}$Tregs in the axillary LNs, unveiling exacerbated Treg migration from inflamed skin to LNs (Figure 2B). As expected, those skin-derived Kaede-red Tregs expressed higher levels of CD103, CD44, CCR4, and CCR5 and lower levels of CD62L and CCR7, compared with the Kaede-green Treg counterparts in the same LNs. However, the difference observed between the two Treg populations was rather modest, perhaps reflecting a major limitation of the experimental system; that is, Kaede-green Treg populations contain not only LN-resident Tregs, but also skin-derived Tregs that have migrated from skin before violet light exposure. Nevertheless, the observations reported by Tomura et al. provide the first experimental evidence for the concept that $\mathrm{CD} 103^{+} \mathrm{CCR} 4^{+} \mathrm{CCR} 5^{+}$Tregs frequently observed in the skin are indeed capable of migrating to draining LNs.

\section{New questions}

Normal human skin and mouse skin are both populated with large numbers of Tregs, and their numbers further increase under inflammatory conditions. What are the mechanisms for maintaining such a large pool of Tregs? Do they divide in situ? Although Tregs were classically regarded as anergic, based on their extremely low in vitro mitotic activities, recent in vivo experiments have revealed their striking proliferative potentials. CD 44 ${ }^{\text {hi }}$ CD62L ${ }^{\text {lo }}$ Treg populations, but not their $\mathrm{CD} 44^{\text {lo }} \mathrm{CD} 62 \mathrm{~L}^{\text {hi }}$ counterparts, constantly incorporate BrdU, a synthetic analog of thymidine, into newly synthesized DNA in lymphoid tissues (20). Even more profound BrdU incorporation has been observed in the Tregs infiltrating Leishmania major-infected skin lesions (21). 
Do skin-derived Tregs found in the LNs migrate back to the skin? To test this, Tomura et al. (17) photoconverted the LN cells and tracked their subsequent trafficking. A majority of the Kaede-red Tregs disappeared from the light-exposed LN within 48 hours, indicating their rapid efflux. Strikingly, a small, but significant, number of Kaede-red Tregs became detectable in DNFB-induced contact hypersensitivity skin lesions, unveiling their previously unrecognized ability to reverse-traffic from LNs to inflammatory skin (Figure 2C). Do the adhesion molecules and chemokine receptors known to mediate Treg migration from the skin to LNs also facilitate reverse Treg trafficking? Alternatively, Tregs may switch their homing receptor expression profiles depending upon the direction of their trafficking. Indeed, Tregs have been reported to employ largely overlapping, but slightly distinct, sets of homing receptors for their trafficking from the blood circulation to peripheral tissues and for their subsequent migration to draining LNs (22).

In the absence of Tregs, DCs and $\mathrm{CD}^{+}$ helper $\mathrm{T}$ cells form stable cell-cell contacts in an antigen-specific manner. Interestingly, Tregs interrupt this cell-cell contact formation by primarily interacting with DCs (23). Because not only Tregs, but also DCs, were reported by Tomura et al. to migrate spontaneously from the skin to draining LNs (Figure 2A) (17), it is tempting to speculate that those Tregs migrating from the skin may dampen the antigen-presenting capacity of the comigrating skin-derived DCs, thereby preventing the activation of autoreactive $\mathrm{CD}^{+}$helper $\mathrm{T}$ cells in the LNs. In this regard, dermal DCs, but not epidermal Langerhans cells, have been reported to simultaneously trigger the production of the proinflammatory cytokine IFN- $\gamma$ by helper $\mathrm{T}$ cells and of the antiinflammatory cytokine IL-10 by Tregs (24).
In summary, Tomura et al. have uncovered a unique ability of Tregs to migrate back and forth between the skin and LNs (17). Their experimental system should serve as an extremely useful model for answering the above and other important questions regarding Treg homeostasis and function.

\section{Acknowledgments}

The authors are supported by NIH grants RO1-AI46755, RO1-AR35068, RO1AR43777, and RO1-AI43232.

Address correspondence to: Akira Takashima, Department of Medical Microbiology and Immunology, University of Toledo College of Medicine, 3000 Arlington Ave., Toledo, OH 43614-5806. Phone: 419.383.5423; Fax: 419.383.3002; E-mail: akira.takashima@utoledo.edu.

1. Woodland DL, Kohlmeier JE. Migration, maintenance and recall of memory $\mathrm{T}$ cells in peripheral tissues. Nat Rev Immunol. 2009;9(3):153-161.

2. Clark RA, et al. The vast majority of CLA+ T cells are resident in normal skin. J Immunol. 2006;176(7):4431-4439.

3. Clark RA, et al. Human squamous cell carcinomas evade the immune response by down-regulation of vascular E-selectin and recruitment of regulatory $\mathrm{T}$ cells. J Exp Med. 2008;205(10):2221-2234.

4. Hirahara K, Liu L, Clark RA, Yamanaka K, Fuhlbrigge RC, Kupper TS. The majority of human peripheral blood CD4+CD25highFoxp3+ regulatory $\mathrm{T}$ cells bear functional skin-homing receptors. J Immunol. 2006;177(7):4488-4494.

5. Chen Z, Benoist C, Mathis D. How defects in central tolerance impinge on a deficiency in regulatory T cells. Proc Natl Acad Sci U S A. 2005; 102(41):14735-14740.

6. Ermann J, et al. Only the CD62L+ subpopulation of $\mathrm{CD} 4+\mathrm{CD} 25+$ regulatory $\mathrm{T}$ cells protects from lethal acute GVHD. Blood. 2005;105(5):2220-2226.

7. Kocks JR, Davalos-Misslitz AC, Hintzen G, Ohl L, Forster R. Regulatory $T$ cells interfere with the development of bronchus-associated lymphoid tissue. J Exp Med. 2007;204(4):723-734.

8. Schneider MA, Meingassner JG, Lipp M, Moore $\mathrm{HD}$, Rot $\mathrm{A}$. CCR7 is required for the in vivo function of CD4+ CD25+ regulatory T cells. J Exp Med. 2007;204(4):735-745.

9. Szanya V, Ermann J, Taylor C, Holness C, Fathman CG. The subpopulation of CD4+CD25+ splenocytes that delays adoptive transfer of dia- betes expresses L-selectin and high levels of CCR7. J Immunol. 2002;169(5):2461-2465.

10. Ochando JC, et al. Lymph node occupancy is required for the peripheral development of alloantigen-specific Foxp3 + regulatory T cells. J Immunol. 2005;174(11):6993-7005.

11. Huehn J, et al. Developmental stage, phenotype, and migration distinguish naive- and effector/ memory-like CD4+ regulatory T cells. J Exp Med. 2004;199(3):303-313.

12. Sather $\mathrm{BD}$, et al. Altering the distribution of Foxp3(+) regulatory $\mathrm{T}$ cells results in tissue-specific inflammatory disease. $J$ Exp Med. 2007;204(6):1335-1347.

13. Suffia I, Reckling SK, Salay G, Belkaid Y. A role for CD103 in the retention of CD4+CD25+ Treg and control of Leishmania major infection. J Immunol. 2005;174(9):5444-5455.

14. Siegmund K, et al. Migration matters: regulatory Tcell compartmentalization determines suppressive activity in vivo. Blood. 2005;106(9):3097-3104.

15. Dudda JC, Perdue N, Bachtanian E, Campbell DJ. Foxp3+ regulatory $\mathrm{T}$ cells maintain immune homeostasis in the skin. J Exp Med. 2008;205(7):1559-1565.

16. Yurchenko E, Tritt M, Hay V, Shevach EM, Belkaid Y, Piccirillo CA. CCR5-dependent homing of naturally occurring CD4+ regulatory $\mathrm{T}$ cells to sites of Leishmania major infection favors pathogen persistence. J Exp Med. 2006;203(11):2451-2460.

17. Tomura $\mathrm{M}$, et al. Activated regulatory $\mathrm{T}$ cells are the major T cell type emigrating from the skin during a cutaneous immune response in mice. J Clin Invest. 2010;120(3):883-893.

18. Ando R, Hama H, Yamamoto-Hino M, Mizuno $\mathrm{H}$, Miyawaki A. An optical marker based on the UV-induced green-to-red photoconversion of a fluorescent protein. Proc Natl Acad Sci U S A. 2002;99(20):12651-12656.

19. Mizuno $\mathrm{H}$, et al. Photo-induced peptide cleavage in the green-to-red conversion of a fluorescent protein. Mol Cell. 2003;12(4):1051-1058.

20. Fisson $\mathrm{S}$, et al. Continuous activation of autoreactive CD4+ CD25+ regulatory T cells in the steady state. J Exp Med. 2003;198(5):737-746.

21. Suffia IJ, Reckling SK, Piccirillo CA, Goldszmid RS, Belkaid Y. Infected site-restricted Foxp3+ natural regulatory $\mathrm{T}$ cells are specific for microbial antigens. J Exp Med. 2006;203(3):777-788.

22. Zhang N, et al. Regulatory T cells sequentially migrate from inflamed tissues to draining lymph nodes to suppress the alloimmune response. Immunity. 2009;30(3):458-469.

23. Tadokoro CE, et al. Regulatory $\mathrm{T}$ cells inhibit stable contacts between CD4+ T cells and dendritic cells in vivo. JExp Med. 2006;203(3):505-511.

24. McLachlan JB, Catron DM, Moon JJ, Jenkins MK. Dendritic cell antigen presentation drives simultaneous cytokine production by effector and regulatory $\mathrm{T}$ cells in inflamed skin. Immunity. 2009;30(2):277-288. 